\title{
Leadership Behavior and Participation in Regional Organization Development
}

\author{
Martin Bokase \\ Université protestante au Congo, DR Congo
}

\begin{abstract}
This article discusses conceptual leadership behaviors and participation in local organizational development. There are four forms of behavior of leaders towards subordinates, namely some that emphasize more on tasks, some are more concerned with relationships, some are concerned with both and some are ignorant of both. The leadership of a head will increase the participation of employees in regional offices in order to achieve productivity from the work for which they are responsible. Personal effectiveness is the leader's effort in achieving goals that meet personal needs rather than to meet organizational interests. These kinds of possibilities happen a lot to a leader who has very big ambitions. This behavioral approach views that leadership can be learned from behavior patterns, and not from the traits of leaders. The reason is that a person's nature is difficult to identify. Some experts believe that behavior can be learned, this means that people who are trained in the right leadership behavior will be able to lead effectively.
\end{abstract}

Keywords: Leader Behavior, Organization, Participation

Received : August 17, 2020

Received in Revised: August 25, 2020

Accepted: August 28, 2020

\section{Introduction}

Behavior does not absolutely determine the success of leadership. The concept of leadership behavior arises because it assumes that the concept of leadership traits is not capable of producing effective leadership because traits are difficult to identify. The effectiveness of this leadership behavior is influenced by several variables. There are four forms of behavior of leaders towards subordinates, namely some that emphasize more on tasks, some are more concerned with relationships, some are concerned with both and some are ignorant of both (De Hoogh \& Den Hartog, 2008).

There are also researchers who say that the embodiment of a leader's behavior with a subordinate orientation is an emphasis on superior-subordinate relationships, the personal attention of leaders on satisfying the needs of their subordinates, and accepting differences in personality, abilities, and behavior that are contained in subordinates.

In a further elaboration, this leadership behavior analysis produces several leadership theories as will be explained below in more detail. This article discusses a conceptual study of leadership behavior and participation in local organizational development.

\section{Relationship between Leadership Theory and Participation}

The participation of members of a group or organization is one of the factors that is quite important in an effort to achieve organizational success to realize participation, so leadership is needed. The leadership of a head will increase the participation of employees in regional offices in order to achieve productivity from the work for which they are responsible. Participation is a process of activities carried out by a person or group to develop manpower and other resources to the agency or system that regulates their life (Conge, 1988; Heinemann et al, 2010; Petress, 2006). 
Participation is a mental and emotional involvement of a person in a group situation that encourages him to contribute to group goals and share responsibility in the effort concerned (Cohen, 2006). A person who participates actually experiences his/her ego involvement which is more than just being involved in a job or task. his involvement means the involvement of his thoughts and feelings. Or you, for example, participate or you can feel it yourself, then you do the activity because according to your mind it is necessary and that your feelings agree or agree to do it.

Participation is a spontaneous engagement accompanied by awareness and responsibility for the interests of the group to achieve common goals. The definition of participation from the above opinion provides an overview of the existence of several main things contained in participation, namely participation means more mental and emotional involvement than physical. Participation that is motivated by mentality and emotion will create awareness that fosters voluntary participation, not joining in or being pressured and forced to participate because coercion is not participation, but "mobilization.

Participation encourages people to donate or support (to Contribute) to group life or "joint life" institutions instead of donating (gifts) to someone, so that any donation (support) to group life from group members will clearly have a very decisive influence on sustainability. group life. Participation encourages people to take responsibility in an activity for the common interest. Because what is donated is voluntary, it creates a sense of "self involved" in the organization.

\section{Leadership Theory and Leadership Effectiveness}

The dimension of leadership, namely task-oriented, shows the extent to which a leader pays attention to the relationship between tasks in the organization and his own subordinates, with the efforts made, such as organizing and giving directions. Relationship Orientation (Managerial Orientation), shows the extent to which a leader can pay attention to the work relationship between himself and his subordinates in the organization, the efforts made include: giving confidence to inspire enthusiasm.

Effective (Managerial Effectiveness), shows the extent to which a leader can influence subordinates so that the success of achieving results in the organization is a mutual success in accordance with the requirements of his position. Reddin pays special attention to the effectiveness dimension, because this dimension is the most determining factor in the leadership style of an organization. The three categories are management effectiveness, apparent effectiveness, and personal effectiveness. Management effectiveness is the extent to which a leader can influence his subordinates so that they can achieve the success of the organization, is a mutual success. Pseudo-effectiveness is an assessment given to a leader based solely on observations of his or her behavior, without judging the results, for example: making decisions quickly, on time, and immediately answering questions. Personal effectiveness is the leader's effort in achieving goals that meet personal needs rather than to meet organizational interests. The possibilities of this kind occur a lot in a leader who has very big ambitions. Paying attention to the concept of effective leadership put forward by Reddin, effective is one measure to determine the level of leadership success in organizations.

Effectiveness is a condition which implies the occurrence of an effect or the desired effect (Cameron, 2015; Sundstrom, De Meuse \& Futrell, 1990; Price, 1972). If someone does an action with a specific purpose that may be desired, then that person is said to be effective if it causes the desired effect, thus it is said that the definition of effectiveness is the occurrence of an effect or the desired result of an action. Concerning the various measures used to 
determine organizational effectiveness resulted in the introduction of nineteen widely used variables the most prominent of which were: (1) overall performance; (2) productivity; (3) employee job satisfaction; (4) profit or level of investment; (5) employee leaving.

Three variables determine organizational effectiveness, namely first, the Initial Variable which is the factors that influence the direction of organizational development and its results. Second, the Intervening Variable, which is a leadership strategy that affects the behavior of human resources in the organization. Third, the output or Order Result Variable, which is the dependent variable that reflects the success of the organizational variables.

Steers (1984: 206), concludes that the criteria most widely used as a measure of effectiveness include adaptability flexibility, productivity, job satisfaction, profitability, resource search. Based on the overall explanation above, (Siagian, 1991: 24-25) provides an overview of leadership effectiveness, namely;

First, there is people's acceptance of good leadership because of experience, education, achievement or because of genetic factors

Second, it requires the ability to "read" situations such as those related to the existing work climate in the organization.

Third, there is the willingness of every member of the organization to act that does not commit selfish behavior.

Organizational effectiveness has an inseparable relationship with the effectiveness of the leadership style applied by a leader in an organization. Bass (in Hersey Blanchard, 1992; 131 132). Suggests that an organization can be clearly distinguished between successful leadership and effective leadership. A leader is said to have a successful leadership style if he can influence the people in the organization to achieve organizational goals. The results achieved cannot be said to be effective as a whole, if the leadership style is not in accordance with the expectations of subordinates. Subordinates only do work because of the power of the leadership position.

If the leadership style of a leader can influence subordinates to do work because he wants to do and feels that he has obtained results, feels consistent with his personal goals, this is what is said with an effective leadership style.

After paying attention to the overall description above, it can be said that the effectiveness of leadership in an organization indicates the ability of a leader to influence his subordinates so that there is a sense of togetherness between leaders and those who are led in achieving organizational goals.

\section{Leadership Effectiveness in Reaching Regional Technical Services and Institutions}

Before discussing further the Regional Technical Services and Institutions as organizations, it can be seen the general definition of the organization. Frochoch (in Riwukaho, 1991; 206) explains that in terms of organizational goals it can be formulated as a system of cooperation for a group of people to achieve common goals, then Sutarto (1984: 36) in an organizational process is a system of cooperation that affects each other between people in groups who work together to achieve certain goals.

Based on this opinion it can be said that the elements in the organization include; there is a group of people, there is a common goal that can only be held, there is cooperation or joint effort between members, there is a division of labor, there is a leader.

The organizational structure of the Services or Regional Technical Institutions is a structure of cooperation between working unit relations in which there are officials, duties, and 
authorities, each of which has a certain role in a complete unit. In order to create a good and effective Regional Service organization and in order for the Regional Office organizational structure to be healthy and efficient, organizational principles must be applied. Thus the principle of organization is a means to be able to create good conditions in order to realize the goals of service organizations. Therefore, the assignment and application of organizational principles in regional offices is an absolute requirement that officials and employees of these offices really understand and appreciate.

As an institution that is synonymous with an organization, the regional offices have had to implement a modern management system like any other private organization. Rasyid (1997: 118) states that government management in the Regional Office must adhere to the principles of effectiveness, efficiency, and innovation in the process of gathering and moving people, obtaining and using money. Organize, use, and maintain equipment and various resources for the creation of the organizational goals of the Regional Office.

In connection with the need for the implementation of modern management in government management at the Regional Office, leadership is one of the factors needed. Rasyid (1997: 118 ) is based on the principles of modern management, in its internal relationship, government leadership is responsible for developing the ability of all-round staff, building vertical and horizontal working relationships that support each other, and creating a passionate working atmosphere, so that the creativity of each apparatus in local government agencies can be encouraged. This in turn will ensure continuous innovation.

The theory of leadership behavior (behavioral theory of leadership) is based on the belief that great leaders are formed or can be formed, not born (leaders are made, nor born). Rooted in behaviorism theory, this leadership theory focuses on the actions of the leader, not on mental or internal qualities. According to this theory, people can learn to become leaders, for example, through training or observation.

There are three dimensions of leadership behavior, which are based on the relationship between three factors, namely task behavior, relationship behavior, and maturity. Task behavior is giving instructions by the leader to subordinates including certain explanations, what to do, when, and how to do it, as well as supervising them closely. Relationship behavior is an invitation conveyed by the leader through two-way communication which includes listening to and involving subordinates in problem-solving. As for maturity, it is the ability and willingness of subordinates to be accountable for the implementation of the tasks assigned to them.

\section{Conclusion}

regional organizational leadership is responsible for developing versatile staff capabilities, building vertical and horizontal working relationships that support each other, and creating a passionate working atmosphere so that the creativity of each apparatus in regional government agencies can be spurred. Great leaders are the result of formation or can be formed, not born (leaders are made, nor born). Rooted in behaviorism theory, this leadership theory focuses on the actions of the leader, not on mental or internal qualities. In addition, organizational effectiveness has an inseparable relationship with the effectiveness of the leadership style applied by a leader in an organization.

\section{References}

Cameron, K. (2015). Organizational effectiveness. Wiley Encyclopedia of Management, 1-4. 
Cohen, J. (2006). Social, emotional, ethical, and academic education: Creating a climate for learning, participation in democracy, and well-being. Harvard educational review, 76(2), 201-237.

Conge, P. J. (1988). The concept of political participation: Toward a definition.

De Hoogh, A. H., \& Den Hartog, D. N. (2008). Ethical and despotic leadership, relationships with leader's social responsibility, top management team effectiveness and subordinates' optimism: A multi-method study. The leadership quarterly, 19(3), 297-311.

Heinemann, A. W., Tulsky, D., Dijkers, M., Brown, M., Magasi, S., Gordon, W., \& DeMark, H. (2010). Issues in participation measurement in research and clinical applications. Archives of physical medicine and rehabilitation, 91(9), S72-S76.

Petress, K. (2006). An operational definition of class participation. College Student Journal, 40(4), 821-824.

Price, J. L. (1972). The study of organizational effectiveness. The sociological quarterly, 13(1), 3-15.

Sundstrom, E., De Meuse, K. P., \& Futrell, D. (1990). Work teams: Applications and effectiveness. American psychologist, 45(2), 120. 